\title{
Direct comparison of [18F]FDG PET/CT with PET alone and with side-by-side PET and $C T$ in patients with malignant melanoma
}

Felix M. Mottaghy • Cord Sunderkötter • Roland Schubert • Petra Wohlfart • Norbert M. Blumstein • Bernd Neumaier • Gerhard Glatting • Cueneyt Özdemir • Andreas K. Buck • Karin Scharffetter-Kochanek • Sven N. Reske

Published online: 1 June 2007

(C) Springer-Verlag 2007

\section{Eur J Nucl Med Mol Imaging (2007)34:XX}

Unfortunately the surname of one of the co-authors, Karin Scharffetter-Kochanek, was rendered incorrectly in the original publication.

The online version of the original article can be found at http://dx.doi. org/10.1007/s00259-006-0358-1.

F. M. Mottaghy $(\bowtie) \cdot$ P. Wohlfart $\cdot$ N. M. Blumstein $\cdot$

B. Neumaier · G. Glatting $\cdot$ A. K. Buck $\cdot$ S. N. Reske

Department of Nuclear Medicine, University Hospital Ulm,

Robert-Koch-Strasse 8,

89073 Ulm, Germany

e-mail: felix.mottaghy@uz.kuleuven.ac.be

C. Sunderkötter $\cdot$ R. Schubert • C. Özdemir •

K. Scharffetter-Kochanek

Department of Dermatology, University Hospital Ulm,

Ulm, Germany

C. Sunderkötter

Department of Dermatology, University Hospital Münster,

Munster, Germany 